\title{
Cameras on or off? There's more than meets the eye with engaging students in online learning.
}

Rebecca Whyley-Smith

Academic Services Librarian, University of Greenwich, UK.

\begin{abstract}
The shift to online learning has caused feelings of isolation and there has been a noticeable lack of engagement by students in this context, owing to uncertainties about the expectations of online etiquette. Research has shown that video cameras are a step in the right direction where building rapport is concerned, but they are not the only tool at our disposal for creating an online community.
\end{abstract}

Keywords: video, camera, online, etiquette, student engagement

\section{Cameras on or off?}

Online learning is a new experience for many students. Some of them feel anxious when in a classroom environment new to them and are noticeably hesitant about participating online, often joining sessions with personal audio and video camera switched off. Rasheed, Kamsin and Abdullah (2020) offer various reasons for this reluctance by students: they may lack confidence or be reserved; they may not have access to appropriate technology; they may simply not have a study space suitable for the purpose. If all participants' cameras are on, the tutor may more readily gauge the group's understanding of a topic from visible nonverbal cues. Furthermore, when all members of the class and the tutor can both see and hear each other, the online experience clearly is far more constructive and engaging for everyone (Castelli and Sarvary, 2021). Certainly, many educators have recognised the likelihood of individual disengagement if any cameras are switched off, for, without them, presenters obviously struggle to create a completely inclusive online community, for some faces and voices are missing. Online presenters often, therefore, find themselves at a disadvantage when tasked with establishing relationships that are crucial to the academic success and satisfaction of students (Martin, 2019).

The 'Academic Support Team' (AST) at the University of Greenwich started delivering online synchronous sessions at the beginning of the pandemic and found that many students join online sessions passively. It is true that students are often unaware of the contrasting dynamics of seminars and lectures: they are uncertain about the etiquette expected of them in each context. New students may be welcomed to university in large induction groups and so may often, in that situation, be required to turn off their cameras and mute their microphones to save on bandwidth. Within seminar or workshop sessions, however, students are expected to turn their cameras on and participate when asked to do so. If these two very different ways of delivering synchronous teaching are not made explicit to students, their confusion over etiquette is to be expected. The added complexity of being online creates uncertainty about the expected level of engagement. It has therefore become 
apparent that clear guidelines are needed, so that all students are aware of the etiquette expected of them when in groups online. Such guidelines, however, are best co-created, so as to ensure that learners are able to control their own learning experience while also meeting the engagement expectations of the educator. Such co-creation could take the form of an open discussion about online etiquette ('netiquette') at the beginning of a live online session, when such a conversation would allow everyone, students and educator, to have a common awareness and understanding of the netiquette to be followed, as well as of expectations and anticipated challenges; the educator would also have the opportunity to explore attitudes and preferences relating to the use of cameras.

The AST developed a range of sessions entitled 'Preparing to Learn Online', covering aspects of digital skills and including online etiquette. The session design allowed all students new to online learning the opportunity to reflect both on the benefits to be gained and the possible challenges to be faced. During the resulting open discussion, the team found that, in most cases, the concerns expressed by some students were resolved by others in the session, so illustrating the value of peer-to-peer discussion in an online environment. Research has shown that "motivation can be enhanced greatly by peer-to-peer interaction, leading to the forming of learning communities. However, this does not happen without the facilitator setting up a conducive environment' (Ryle and Cumming, 2007, p.42). Rhim and Han (2020) state that the role of the educator in the online environment involves not only providing information but also motivating and empowering students to enrich their learning experience. Activities to ensure that learners can engage with each other are therefore a necessity in online lesson design.

Feedback from the live sessions conducted by the AST indicated that students enjoyed the informal conversations between presenting staff: they felt part of a welcoming community. Research has shown that having the "instructor disclose personal experiences, a personal photo and video communications ultimately strengthens the online learning experience" (Caskurlu et al., 2021, p.8). It therefore became apparent that the educator should be a positive role model, for to follow personal expected netiquette encourages reciprocity by the students in the group. The personalisation of synchronous sessions could also be brought into asynchronous learning. Photos, videos and discussion forums are a way to bring about interactivity and all play an important role in social learning.

Turning cameras on does give students the opportunity to build rapport, but there are other tools that can be used to ensure that students are able to interact with each other and the material at hand. Harnessing such 'Teams' functions as chat, whiteboard and breakout rooms, together with 'Mentimeter', is a meaningful use of technology to check understanding and build a sense of belonging. Answering questions, taking part in a quiz or holding discussions in smaller groups or in the chat function are all experiences that build a social learning environment. Online learning therefore requires an adjustment of perspectives. Learners should not be seen as passive recipients, but as autonomous, active learners who take control of their own learning experience by taking advantage of the tools that are made available (Rhim and Han, 2020).

In conclusion, the use of video cameras in synchronous teaching is an important step towards successful encouragement of engagement, but it is not the only tool at our disposal. Post-pandemic pedagogy should reflect the importance of creating an online community to ensure that students have every possible opportunity to engage, just as they 
would in a face-to-face environment. It should also not dictate boundaries but open a dialogue between educator and learners about the expectations of good netiquette.

\section{Reference list}

Caskurlu, S., Richardson, J.C., Maeda, Y. and Kozan, K. (2021) 'The qualitative evidence behind the factors impacting online learning experiences as informed by the community of inquiry framework: A thematic synthesis.' Computers and Education, 165. doi:

https://doi.org/10.1016/..compedu.2020.104111

Castelli, F.R. and Sarvary, M.A. (2021) 'Why students do not turn on their video cameras during online classes and an equitable and inclusive plan to encourage them to do so.' Ecology and Evolution, 11(8), 3565-3576. doi: https://doi.org/10.1002/ece3.7123

Martin, J. (2019) 'Building relationships and increasing engagement in the virtual classroom: practical tools for the online instructor.' Journal of Educators Online, 16(1). Available at: https://eric.ed.gov/?id=EJ1204379 (Accessed: 28 May 2021).

Rasheed, R.A., Kamsin, A. and Abdullah, N.A. (2020) 'Challenges in the online component of blended learning: A systematic review.' Computers and Education, 144. doi: https://doi.org/10.1016/j.compedu.2019.103701

Rhim, H.C. and Han, H. (2020) 'Teaching online: Foundational concepts of online learning and practical guidelines.' Korean Journal of Medical Education, Korean Society of Medical Education, 32(3), 175-183. Available at: https://pubmed.ncbi.nlm.nih.gov/32894921/ (Accessed 26 May 2021).

Ryle, A. and Cumming, K. (2007) 'Reflections on Engagement in Online Learning Communities.' International Journal of Pedagogies and Learning, 3(3), 35-46. doi: https://doi.org/10.5172/ijpl.3.3.35 